\title{
CSR Strategy in Industrial City to Achieved Competitive Advantage
}

\author{
S. Sarjana \\ Doctoral Program in Business Management \\ Universitas Padjadjaran \\ sri14024@mail.unpad.ac.id
}

\author{
N. Khayati \\ SMAN 1 Cikarang Utara \\ nurkayati.pch@gmail.com
}

\begin{abstract}
CSR strategy become manufacture's policy to effective controlling all of resources and capabilities. CSR activities needed powerful commitment to conduct business especially focus in economically, socially and environmentally. Strategic organizational through resources and capabilities determine the type of CSR strategy deployed in manufacturing. These valuable and unique aspects of CSR strategy be attributed to the moral and ethics of CSR activity. This study empirically investigates whether there is an effect of CSR strategy to achieve competitive advantage at industrial city. The authors conducted a survey to test the hypotheses and design a SEM to analyze them. The result showed that the CSR strategies have positive effect on competitive advantage. Resources and capabilities have positive effect on CSR strategy. Furthermore, this research is expected to provide for management in industrial manufacturing have valuable suggestions for management practices to increase for implemented of CSR strategy and how achieved the manufacturing goals especially to win of competitive advantage in business.
\end{abstract}

Keywords- Competitive Advantage, CSR Strategy, Resources, Capability

\section{INTRODUCTION}

Issue of global organizational learning from CSR practices carried out in different business units, divisions, and country operations [1]. Change is an inevitable factor in the development of any organizations and can be adapted, adopted, piloted through benchmarking in order to compete in this competitive business environment [2]. The competitive advantage development strategies section allows the decisionmaker to define the company determination, the market definition, the value of the product and the marketing plan [3]. There must be a focus on creating a competitive advantage by emphasizing cost, quality and on time delivery [4]. Business to business provides many growth opportunities and benefits for firms, such as cost reductions, efficiency improvements, better supplier relationships, access to global markets, new customers and suppliers, productivity improvements, increased profits and gains in competitive advantage [5]. Firms must be prepared in advance for situations, opportunities and threats in the future and firms must have a long-term view to be successful and develop their capabilities in the future [6]. Internal firm capabilities and resources have not been dynamic enough in the past to warrant the use of transient that too might change in the new business environment [7]. On this basis capabilities are conceived as distinct behavioral patterns, which are complex in nature involving both formal and informal processes [8]. Organizational capabilities are depicted as critical success factors and these days nearly every organization wants to be perceived as being capable of doing something in an outstanding manner [9]. The quantity is resources that can be mobilized in emerging economy contexts. What makes their resource base distinct from advanced economy firms are their overall lower costs such as labor, production, R\&D, marketing, product development [10]. The resource based view indicates that organizations should focus on combinations of rare resources that promote an organization's competitive advantage [11]. The aim of this study is expected to implement a CSR strategy in order to winning the competitive advantage especially business at industrial manufacturing. The company's participation to contribute CSR activities is needed to sustain the existence of industries especially focus on improvement in business, social and environmental.

\section{LITERATURE REVIEW}

\section{A. CSR Strategy}

CSR is a continued promise by companies to act ethically, to contribute to sustainable economic development, and to contribute to improvement of quality of life of its employees, their families, as well as local communities and society as a whole [12]. CSR is a company's sense of responsibility towards the community \& environment that is ecological \& social in which it operates. Companies express this citizenship in the following ways, through their waste and pollution reduction processes, by contributing towards educational and social programs, by earning adequate returns on the employed resources [13]. CSR is a process with the aim to embrace responsibility for the company's actions and to encourage a positive impact through its activities on the environment, consumers, employees, communities, stakeholders and all other members of the public sphere who may also be considered stakeholders [14]. CSR refers to companies taking responsibility for their impact on society, reflected by the intention, actions and performance of specific enterprises to strive to maximize social welfare during the term of their existence under specific institutional arrangements [15]. CSR is an organization commitment to conduct its business in an economically, socially and environmentally and in sustainable manner whilst balancing the interests of a diverse range of 
stakeholder and another definition CSR refers to the responsibility taken by organizations and the impact of their activities on customers, employees, shareholders, communities and the environment in all aspects of their operations [16]. CSR defined as the ethical behavior of a company towards the society and CSR is basically a concept whereby companies decide voluntarily to contribute to a better society and a clean environment and CSR is represented by the contributions undertaken by companies to society through its business activities and its social investment [17].

CSR strategy consists of proactive and reactive. The planning required to proactively engage in CSR suggests that consumers may perceive the initiative to be more strategicdriven, compared to a reactive initiative. Consumers are also likely to assign higher values-driven attributions to a proactive versus reactive initiative. Compared to reactive CSR, there is typically no pejorative information surrounding a proactive CSR initiative [18]. Furthermore, described proactive CSR is represented in this study by a pattern of responsible business strategies that support the economic, social and environmental principles of sustainable development at a level over and above that required to comply with government regulations [19]. Characteristics or CSR pattern included of reactive CSR, turn-key CSR, issue-based CSR, recipient-based CSR, integrated CSR [20].

CSR strategy will become more rule based by firms who aim to effectively manipulate and control their capabilities and resources that are valuable, rare and not easily imitated without a perfect substitute available to generate sustainable competitive advantages [21]. CSR strategy processes including the requirement for informative communications rather than persuasive negotiations, and the absence of resistance within the organizational community [22]. Strategic CSR focuses on social innovation through company products and services [20]. Dimension of proactive CSR include economic growth and prosperity, social cohesion and equity, and environmental integrity and protection [19]. General framework for CSR level such as personal driver, strategic driver, reactive driver. Personal drivers include the attitude, interests, and beliefs of top management toward the use of company resources for social causes. Reactive drivers include the adoption of CSR activities under public pressure to head off criticism [23]. Social and religious values are important antecedents of CSR strategy and implementation [20].

\section{B. Competitive Advantage}

Competitive advantage is broadly covered in the literature in terms of cost reductions, differentiation, growth, and quality [24]. Competitive advantage is obtained when an organization develops or acquires a set of attributes that allow it to outperform its competitors [7]. The greatest impact on competitive advantage is a component of knowledge acquisition [25]. The major managerial implication should strengthen their development and rational culture to attain and sustain a competitive advantage [26]. Competitive advantage is the one that characterizes that makes something better than all its competitors [3].
Dimension competitive advantage included cost, quality \& delivery [4]. Company can create and deliver more economic value than its competitors simultaneously by increasing the profit and offering the higher benefit to the consumers rather than to the competitors as following condition of competitive advantage [27]. The ability to perform an activity better than its competitors will lead to a sustainable competitive advantage [3]. Ambitious companies should always be concerned with how to achieve and sustain a competitive advantage [24]. Competitive advantages can be created through innovation, efficiency, quality, and customer responsiveness [2]. Knowledge can be considered as a competitive advantage that organizations can hardly imitate its competitors [25]. Product innovation and service innovation affect competitive advantage with competition in foreign countries and needs to be a lifting capacity of supporting industries that can produce parts with quality, at a low cost which are delivered on time [4].The way for current business environment has evolved, opportunities for leveraging competitive advantage are transient [7]. Culture can only affect competitive advantage through absorptive capacity and innovation [26].

\section{Capability}

Capabilities refer to the freedoms one has to do these valuable activities or reach these valuable states [28]. Capabilities refer to a corporation's ability to exploit its resources. They consist of business processes and routines that manage the interaction among resources to turn inputs into outputs [29]. Capability is the capacity for a set of resources to perform a task or an activity in an integrative manner [30]. The concept of capability as the various combinations of functioning (beings and doings) that the person can achieve [31]. The capability approach has made a substantial contribution to shaping the emergent paradigm to which these various initiatives relate, but that further development of the paradigm is required [28]. In the resource based view, organizational capabilities have been identified as one major source for the generation and development of sustainable competitive advantages [32].

Four main ways in which the capability approach has contributed to a new approach for the social sciences and policy thinking. First, it argues for human beings and their quality of life to be the central focus of policy. Second, it conceives human freedom and the ability to make decisions that affect one's life as central to human dignity. Third, it reestablishes ethics at the heart of policy-making. Fourth, it sets itself out as an approach and not a theory [28]. In case of superior performance and a unique historical development, capabilities are assumed to build the foundation for sustainable competitive advantage [9]. Resources and capabilities are essentially unproductive in isolation. The key to attaining a competitive advantage is the exploitation of a valuable resource-capability combination [11]. The capability approach constitutes a significant contribution to social theory but its potential is diminished by its insufficient treatment of the social construction of meaning [28]. There are three critical components of dynamic capabilities, which are capability possession that is having distinctive resources, 
capability deployment included allocating distinctive resources and capability upgrading included dynamic learning and building new capability [33]. The primary premise of the dynamic capabilities framework is that a firm has operational capabilities and resources that are directly involved in enterprise performance by converting inputs into outputs and dynamic capabilities that influence enterprise performance indirectly by updating, integrating and reconfiguring a firm's existing operational capabilities and resources [34]. A firm that understands how a given dynamic capabilities is linked to its existing operational capabilities will be more successful at renewing its operational capabilities and gaining a competitive advantage than firms that lack such understanding [35]. The policy significance of the capability approach can be further strengthened by paying greater consideration to the political economy of policy decision-making processes and the ways in which conflicts and distributions of power are institutionalized [28].

\section{Resources}

Resources are an organization's assets and are thus the basic building blocks of the organization. Resources include tangible assets such as its plant, equipment, finances, and location, human assets, number of employees, skills, motivation and intangible assets such as its technology such as patents \& copyrights, culture, and reputation [29]. Resources are inputs into a firm's production process, such as capital equipment, the skills of individual employees, patents, finances, and talented managers [30]. Resource-based insights as developed in advanced economy contexts do not directly apply to the internationalization process of emerging economy [10]. A compliment to this external view in the early stages of the strategic planning process such as the situation analysis stage is the resource based view, which takes an internal orientation by systematically evaluating relevant organizational resources, which could present potential competitive advantages [36]. The corporations resources become sources of competitive advantage if they achieve the following principles consist of valuable, rare, imitable and have no strategic equivalent [37]. Resources and capabilities are part of the firm's internal aspect which customers do not perceive or value [38]. Resource based view becomes apparent during resource deployment for strategy implementation [36]. The identification of social and behavioral features of resources and capabilities has been informed by insights from evolutionary economics [39]. Resources represent the strengths and weaknesses of the organization [40].

Firm resources and capabilities, such as organizational structure, contribute to the development of competitive strategies that seek to satisfy customers' needs better than competitors and hence improve firm performance. Resources and capabilities are not valuable in themselves [14]. Resource based view perspective only takes managerial resources and time into consideration [36]. This kind of resources, as outlined, can help companies to choose and implement strategies [41]. Considering that in emerging economies competition appears to be less sophisticated, research comparing value creation in the same industry but in different economic contexts can provide some appealing conclusions about which resources are more valuable in each context [42].

\section{CONCEPTUAL FRAMEWORK \& HYPOTHESES}

The competitive advantage model includes the factors of marketing, product, value and differentiation [3]. Sustainable competitive advantage requires manager ongoing development of resources, searching for new, more efficient combination of them new ways of organization and management of the company [43]. Information infrastructure capability has the potential to increase organizational competitive advantage [44].

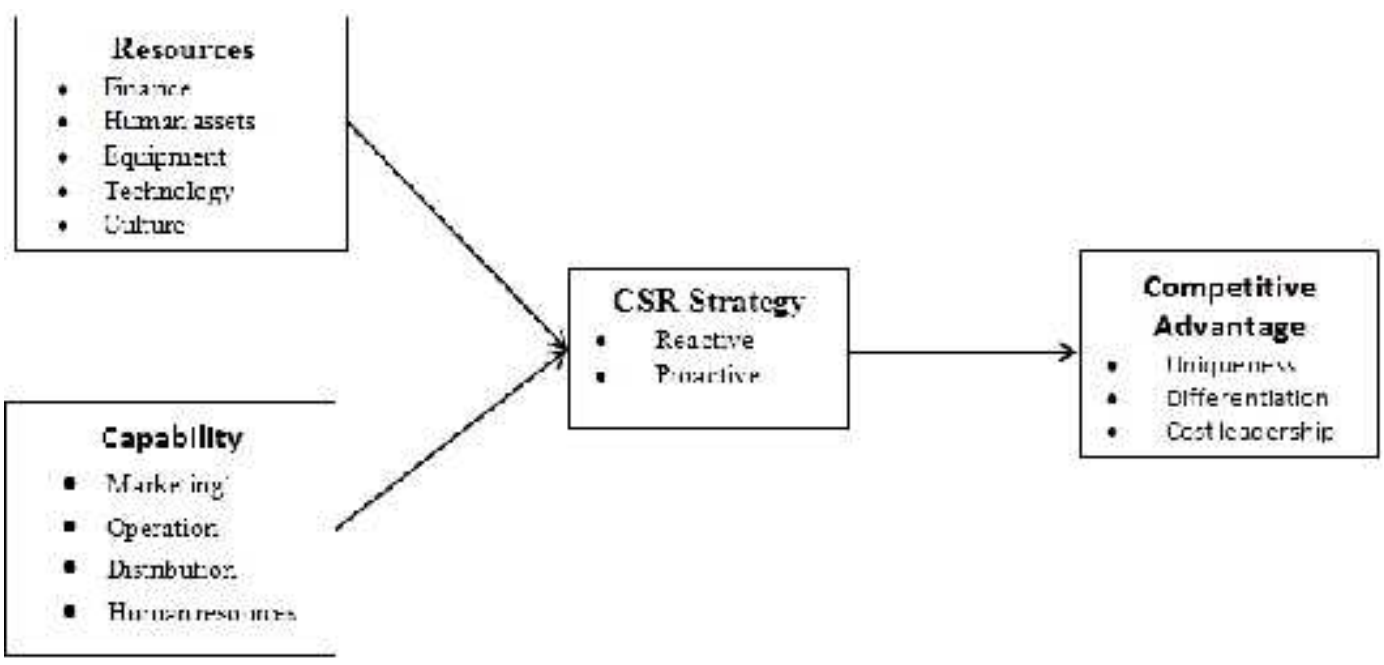

Fig. 1. Research Paradigm

Hence, and based on the previous literature review we propose:
$\mathrm{H}_{1}$ : Resources have positive direct effect on CSR strategy

$\mathrm{H}_{2}$ : Capability have positive direct effect on CSR strategy 
$\mathrm{H}_{3}$ : CSR Strategy have positive direct effect on competitive strategy

\section{METHODOLOGY}

The main objective of this research was to investigate the influence of CSR strategy and implication on competitive advantage at industrial city. This study was aimed for industrial manufacturing that have implemented CSR strategy as a sampling frame. Data analysis for the research was conducted by the researchers using the Lisrel program to assist in the analysis of the variables as well as the application of the structural equation modeling analysis of the causal relationship between variables. The size of the sample has to be large enough to be used in the data analysis by the application of the model equations with the structure and the distribution of data [45]. Data was therefore collected from 200 engaged in industrial manufacturing by use of stratified sampling. Subsequently, simple random sampling was applied for each stratified random sampling to the data collected from the surveyed population. Population consists of manufacturing in industrial city at Bekasi, Indonesia. The data was collected from industrial manufacturing distributed through email and face to face conversations. From the target sample of questioners, 148 questioner were completed, 52 were discarded as incomplete. Hence, the final response rate was 74 percent. Data were gathered during the month of Feb until March 2016. The statistical results obtained from the questionnaire were analyzed. The final questionnaire comprised four variables included resources, capability, CSR strategy and competitive advantage.

\section{RESULTS AND DISCUSSION}

Table 1 show that profile of respondents, the result reveals that $29 \%$ of the respondents have less 3 years of existence and $20 \%$ of the respondents worked over then 10 years. With regard to the number of employee, $49.5 \%$ have biggest employee with around 26-100 employees and the most of them around $53.4 \%$ respondents with background activities of automotive industries as the most respondents and have influence in this survey.

TABLE I. DEMOGRAPHIC RESPONDENT

\begin{tabular}{|c|c|c|c|}
\hline Themographiss profils. & Catronry & No of mspondent & $\sigma_{\%}$ \\
\hline \multirow[t]{3}{*}{ Year's of existence } & Less 3 vesis & 43 & 29 \\
\hline & 310 vears & 76 & 51 \\
\hline & Uver 10 year & $2 y$ & 20 \\
\hline \multirow[t]{4}{*}{ No. «: T стाрloyect } & I.cas 25 & 21 & 14 \\
\hline & $26 \quad 106$ & 73 & 44.5 \\
\hline & $101 \quad 1000$ & 37 & 25 \\
\hline & Over 1000 & 17 & 11.5 \\
\hline \multirow[t]{3}{*}{ Brack,grourad aclivilies } & Autumblive & 79 & 5.3 .1 \\
\hline & Tleel ronie:s & 39 & 26.3 \\
\hline & Food \& bovcrages & 30 & 20.3 \\
\hline
\end{tabular}

Analysis model shows that research model fits the data. Further, testing the hypothesis indicates an analysis of the influence of the resources, capability, CSR strategy and competitive advantage. Figure 2 shows the standardized coefficients for the structural relations tested. As can be seen, the goodness of fit indices for the structural model show a good fit and therefore it is feasible to test the proposed hypotheses. $\mathrm{H}_{1}$ and $\mathrm{H}_{2}$ is supported $\left(\beta_{1}=0.39 ; \beta_{2}=0.43\right)$ as resources and capability on CSR strategy. That means described that resources and capability have a positive direct effect on CSR strategy. $\mathrm{H}_{3}$ are confirmed $\left(\beta_{3}=0.84\right)$ is CSR strategy on competitive advantage. CSR strategy has a positive direct effect on competitive advantage. These results give empirical support to the idea that the efforts made by industrial manufacturing will be rewarded by the projection of a positive CSR strategy that will lead to increasing competitive advantage. Therefore, the proposed model is totally supported by the results. 


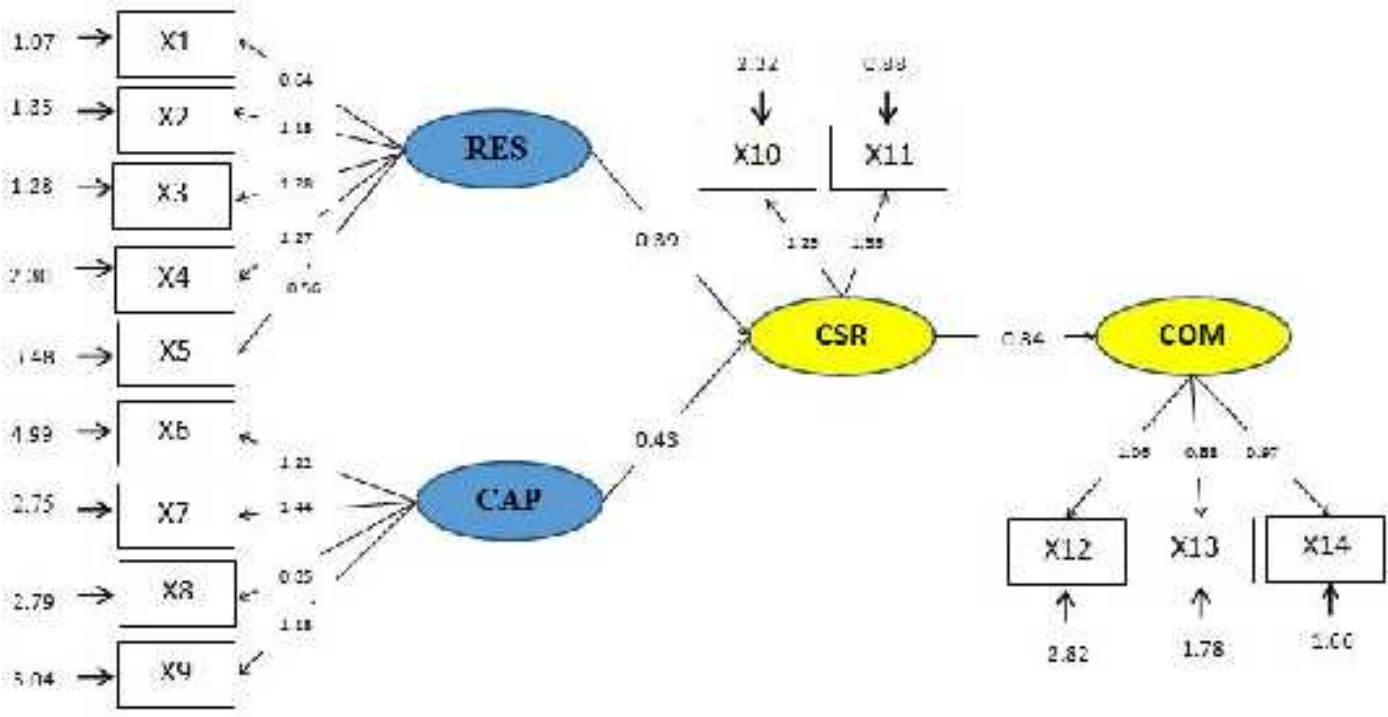

Fig. 2. Structural model estimation

The model indicated a confirmatory factor analysis procedure to access all constructs involved in the study. The data are the score of 148 respondents in industries on construct activities. The structural model result shows the achieved stable model fit estimation. The indicators of fit: $\mathrm{Cmin} / \mathrm{df}=$ $3.175(\mathrm{Cmin}=231.75, \mathrm{df}=73) ; \mathrm{GFI}=0.80 ; \mathrm{RMR}=0.39 ; \mathrm{NFI}$ $=0.79 ; \mathrm{CFI}=0.84 ;$ RMSEA $=0.13$. Table 2 empirically shows that resources and capability have a significant influence $\left(\beta_{1}=0.39, \beta_{2}=0.43, \mathrm{p}=.0000\right)$ on CSR strategy, and CSR strategy has a highly significant influence $\left(\beta_{3}=0.84\right.$, $\mathrm{p}=.0000)$ on competitive advantage. These indices suggested that the structural model provided a good fit to the data at hand and yielded a corroborating value for the good model fit.

TABLE II. SEM RESULT

\begin{tabular}{|c|c|c|}
\hline Hypotheses Structural Relationship & $\begin{array}{l}\text { Standard Coefficient } \\
\text { (Robust t-raluc) }\end{array}$ & Contrast \\
\hline Kescurces $\rightarrow$ CSSR stral=gy & $0.39(2.86)$ & A:cepled \\
\hline Capalilitv - CSk stral=gy & $0.45(2.50)$ & Aicepled \\
\hline CSR stratesy - competitive advantage & $0.81(1.65)$ & Accepted \\
\hline $\mathrm{NFI}-0.79 \mathrm{NNFI}-0.80 \mathrm{CFI}-0.81 \mathrm{IFI}-0.85$ & & \\
\hline$\gamma^{\prime}=25985, \mathrm{df}=73, \mathrm{y}=8000$ & RMST:A=0 13 & \\
\hline
\end{tabular}

\section{CONCLUSION \& SUGGESTIONS}

This study empirically investigates whether there are an effect resources, capabilities, CSR strategy and competitive advantage in industrial city. The authors conducted a survey to test the hypotheses and design a SEM to analyze them. The result ensure that resources and capabilities have positive direct effect on CSR strategy in industrial city. Dynamic and utility capabilities are the key significant capabilities for achieving organizational competitive advantage [44]. Another finding described that CSR strategy has positive direct effect on competitive advantage especially for implemented at industrial city. CSR strategy will become more rule based by firms who aim to effectively manipulate and control their capabilities and resources that are valuable, rare and not easily imitated without a perfect substitute available to generate sustainable competitive advantages [21]. Our empirical evidence supports all the proposed hypotheses. Moreover, this study described that CSR strategy has a positive direct effect on competitive advantage. CSR strategy will become more manufacture's policy to effective control and coordinate their capabilities and resources that are valuable and uniqueness with commitment to conduct its business in an economically, socially and environmentally. Proactive CSR involves business strategies and practices adopted voluntarily by firms that go beyond regulatory requirements in order to manage their social responsibilities, and thereby contribute broadly and positively to society [19]. Strategic organizational through resources and capabilities may determine the type of CSR strategy deployed in manufacturing. These valuable and unique aspects of CSR strategy be attributed to the moral and ethics of CSR activity.

Such findings are relevant since they add several contributions to the existing strategic management literature. 
First of all, they provide empirical evidence of industrial manufacturing are influencing CSR strategy and competitive advantage. Since previous works have essentially focused on the role of sustainable manufacturing, this study adds to our understanding of the effect of CSR strategy and competitive advantage. By providing relevant information to stakeholder about industrial manufacturing, the identity based on CSR strategy and competitive advantage. Second, we show that the principles of the differentiated of thought regarding the effect CSR strategy on competitive advantage are met in the research supporting recent studies. Organizational structures as a resource or capability that influences the development of competitive strategy for the achievement of competitive advantage [38]. The present study has a number of implications for strategic management practitioners. In order to contribute in competitive advantage, resources and capabilities must contribute to delivering products and services for which customers are willing to pay a profitable price [46]. The resource based view focus is on competitive advantage based in internal resources an organization develops or hires in order to implement specific product market strategies [47]. This should give in industries that they need to justify the policy that are associated with sustainable manufacturing issues. Therefore, it would be interesting to replicate this study but considering various stakeholders to ensure that our results are extrapolated to using another variable especially for manufacturing study such as dynamic capability, knowledge resources, environmental turbulence, manufacturing performance and manufacturing capability.

\section{REFERENCES}

[1] Cruz, L.B., \& Boehe, D.M. (2010). How do Leading Retail MNCs Leverage CSR Globally? Insights from Brazil. Journal of Business Ethics, 91, 243-263.

[2] Attiany, M.S. (2014). Competitive Advantage Through Benchmarking: Field Study of Industrial Companies Listed in Amman Stock Exchange. Journal of Business Studies Quarterly, 5(4), 41-51.

[3] Schreyogg, G., \& Kliesch-Eberl, M. (2007). How Dynamic Can Organizational Capabilities Be? Towards A Dual-Process Model of Capability Dynamization. Strategic Management Journal, 28, 913-933.

[4] Chamsuk, W.,Phimonsathien, T., \& Fongsuwan, W. (2015). Research and Development (R\&D) Capabilities and Innovation Capability That Affect The Enterprise Competitive Advantage in The Thai Automotive Parts Industry: SEM Approach. International Journal of Arts \& Sciences, 08(02), 441-457.

[5] Fauska, P., Kryvinska, N., \& Strauss, C. (2013). The role of e-commerce in B2B markets of goods and services. International Journal of Services, Economics, and Management, 5(1-2), 41-71.

[6] Akman, G., \& Yilmaz, C. (2008). Innovative capability, innovation strategy and market orientation: An empirical analysis in Turkish software industry. International Journal of Innovation Management, 12(1), 69-111

[7] Wheelen, T.L., \& Hunger, J.D. (2012). Strategic Management and Business Policy: Toward Global Sustainability. New Jersey: Pearson.

[8] Dosi, G., Nelson, R.R., \& Winter, S.G. (2000). Introduction: the nature and dynamics of organizational capabilities. In The Nature and Dynamics of Organizational Capabilities, Dosi, G., Nelson, R.R., \&Winter, S.G. (eds). Oxford University Press: New York; 1-22.

[9] See, G. (2009). Harmonious Society and Chinese CSR: Is There Really a Link. Journal of Business Ethics, 89, 1-22.
[10] Khatun, K.M., Islam, M.A., Noor, I.M., \& Sa'aban, S. (2015). A Review on Trends of Corporate Social Responsibility. The Social Science, 10(2), 166-170.

[11] Priem, R.L., \& Butler, J.E. (2001). Is the resource-based 'View' a useful perspective for strategic management research?. Academy of Management Review, 26(1), 22-40.

[12] Cierna, H., \& Sujova, E. (2015). Parallels Between Corporate Social Responsibility and The EFQM Excellence Model. MM Science Journal, 670-676.

[13] Kaveh, D., Bamipour, E.M., \& Far, M.S. (2015). The Relationship between Knowledge Management and Competitive Advantage: A Case Study in Small and Medium-Sized Companies in the Packaging Industry of Khorasan Razavi. European Online Journal of Natural and Social Sciences, 4(1), 650-659.

[14] Gaurangkumar, B. (2015). Cost Benefit Analysis of Corporate Social Responsibility (CSR). Journal of Advances in Management, 8(5), 7-12.

[15] Kash, B.A., Spaulding, A., Gamm, L.D., \& Johnson, C.E. (2014). Healthcare Strategic Management and the Resource Based View. Journal of Strategy and Management, 7(3), 251-264

[16] Kotler, P., \& Keller, K.L. (2011). Marketing Management. New Jersey: Prentice Hall.

[17] Wang, H. (2014). Theories for Competitive Advantage. In H. Hasan (Eds.), Being Practical with Theory: A Window into usiness Research, 33-43.

[18] Newbert, S.L. (2008). Value, rareness, competitive advantage, and performance: a conceptuallevel empirical investigation of the resourcebased view of the firm. Strategic Management Journal, 29(7), 745-768.

[19] Vijayalakshmi, N.V., \& Nandhini. (2012). A Comparative Study on Corporate Social Responsibility of Select Pharmaceutical Private Sector Companies in India. Journal of Radix International Educational and Research Consortium, 1(11), 1-26.

[20] Teece, D.J., Pisano, G., \& Shuen, A. (1997). Dynamic Capabilities and Strategic Management. Strategic Management Journal, 18(7),509-533.

[21] Chung, M., \& Safdar, N. (2014). Firms Strategic CSR Choices during the Institutional Transition in Emerging Economies. International Review of Management and Business Research, 3(3), 1709-1727.

[22] Smirat, I.M.H., Abdullah, O.Y., \& Shariff, M.N.M. (2014). Strategy, Structure, and Family Firm Performance: The Relationships of the Resource-Based View And The Contingency Approach. Australian Journal of Business and Management Research, 4(3), 1-8.

[23] Sen, A. (1992). Inequality Re-examined. Oxford: Clarendon Press.

[24] Elbeltagi, I., Hamad, H., Moizer, J., \& Abou-Shouk, M.A. (2016). Levels of Business to Business E-Commerce Adoption \& Competitive Advantage in Small \& Medium-Sized Enterprises: A Comparison Study Between Egypt and the United States. Journal of Global Information Technology Management, 19(1), 6-25.

[25] Kazlauskait , R., Autio, E., Gelbūda, M., \& Šarap, T. (2015). The Resource-based View and SME Internationalization: An Emerging Economy Perspective. Entrepreneurial Business and Economics Review, 3(2), pp. 53-64.

[26] Adriansah, A., \& Afiff, A.Z. (2015). Organizational Culture, Absorptive Capacity, Innovation Performanceand Competitive Advantage: An Integrated Assesment in Indonesian Banking Industry. The South East Asian Journal of Management, 9(1),70-86.

[27] Sakas, D., Vlachos, D., \& Nasiopoulos. (2014). Modelling strategic management for the development of competitive advantage, based on technology. Journal of Systems and Information Technology, 16(3), 187-209.

[28] Deneulin, S., \& McGregor, J.A. (2010). The capability approach and the politics of a social conception of wellbeing. European Journal of Social Theory, 13(4), 501-519.

[29] Winter, S.G. (2003). Understanding dynamic capabilities.Strategic Management Journal, 24(10): 991-995.

[30] Hongjun, X. (2014). Will Institutional Distance Affect Multinational Firms' CSR Performance in a Host Country. Journal of China Economist, 9(5), 108-122.

[31] Sharp, Z., \& Zaidman, N. (2010). Strategization of CSR. Journal of Business Ethics, 93, 51-71. 
[32] Barney, J.B. (1991). Firm Resources and Sustained Competitive Advantage. Journal of Management, 17(1), 99-120.

[33] Marichova, A. (2014). The dynamic capabilities of the firm - a major factor for sustainable competitive advantage: A study of Bulgarian construction industry. Ovidius University Annals Series:Civil Engineering, 16, 53-64.

[34] Torugsa, N. A., O’Donohue, W., \& Hecker, R. (2012). Capabilities, Proactive CSR and Financial Performance in SMEs: Empirical Evidence from an Australian Manufacturing Industry Sector. Journal Business Ethics, 109, 483-500.

[35] Gao, T., \& Tian, Y. (2014). Mechanism of Supply Chain Coordination based on Dynamic Capability Framework - The mediating Role of Manufacturing Capabilities. Journal of Industrial Engineering and Management, 7(5), 1250-1267.

[36] Kaur, P. (2015). Corporate Social Responsibility: Present Scenario in India. Journal of Commerce \& Management Thought, 6(3), 496-511.

[37] Barney, J.B., Wright, M., \& Ketchen, D. (2001). The resource-based view of the firm: Ten years after 1991. Journal of Management, 27, 625641

[38] Srisuphaolarn, P. (2013). From Altruistic to Strategic CSR: How Social Value Affected CSR Development; A Case Study of Thailand. Social Responsibility Journal, 9(1), 56-75.

[39] Helfat, C.E., \& Peteraf, M.A. (2003). The dynamic resource based view: capability life cycles. Strategic Management Journal, 24(10): 997-1010.
[40] Duncan, W.J., Ginter, P.M., \& Swayne, L.E. (1998). Competitive advantage and internal organisational assessment. The Academy of Management Executive (1993-2005), 6-16.

[41] Barney, J.B., Ketchen, Jr.D., \& Wrigh, M. (2011). The Future of Resource-Based Theory: Revitalization or Decline? Journal of Management, 37(5), 1299-1315.

[42] Ling, L.S., Tee, O.P., \& Eze, U.C. (2014). Conceptualizing Knowledge Management and Information Infrastructure Capability for Competitive Advantage: A Malaysian Perspective. Journal of Global Information Technology Management, 17, 117-138.

[43] Mark, D., Groza, M.D., Pronschinske, M.R., \& Walker, M. (2011) Perceived Organizational Motives and Consumer Responses to Proactive and Reactive CSR. Journal of Business Ethics, 102, 639-652.

[44] Luo, Y. (2000). Dynamic Capabilities in International Expansion. Journal of World Business, 35(4), 355-378.

[45] Hair, J., Black, W.C., Babin, B.J. \& Anderson, R.E. (2010). Multivariate analysis, 7th edition. New Jersey: Pearson Education International.

[46] Ambrosini, V., Bowman, C., \& Collier, N. (2009). Dynamic capabilities: An exploration of how firms renew their resource base. British Journal of Management, 20(1), 9-24.

[47] Reniati. (2016). Creating Human Resource Development Strategy Through The Strengthening of Human Capital, Structural Capital, and Relational Capital to Improve Local Competitive Advantage. Review of Integrative Business Economics Research, 5(2), 239-249. 